\title{
Cinco pacientes, once colgajos libres: resultados a largo plazo
}

\section{Five patients, eleven free flaps: Iong-term results}

\author{
Olvera Caballero, C.*
}

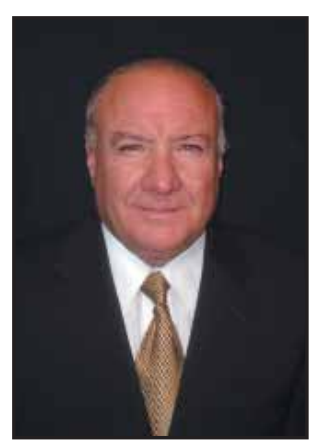

Olvera Caballero, $\mathrm{C}$.

\section{Resumen}

Los colgajos libres resuelven problemas complejos. En situaciones en donde existe gran pérdida de tejidos u otros métodos reconstructivos han fracasado se puede lograr restablecer la forma y la función utilizándolos. En este trabajo se presentan cinco pacientes en los que se usaron once colgajos libres ( 2 por paciente en cuatro casos, tres en otro) y sus resultados a largo plazo con un mínimo de seguimiento de 7 años y un máximo de 17 años. Las indicaciones para utilizar más de un colgajo libre en un paciente son: reponer un primer colgajo perdido, por complejidad del problema, por experiencia del cirujano o por deseo expreso del paciente para una reconstrucción similar. En nuestra serie, la complejidad del problema fue la principal indicación de usar este método doble y triple. Cuatro pacientes recibieron los colgajos en los miembros inferiores y uno en la cara. Las etiologías encontradas fueron: secuelas de quemaduras en dos casos, secuelas posttraumáticas en otros dos y secuelas postquirúrgicas y de mielomeningocele en uno. Se utilizaron cuatro colgajos de dorsal ancho, cinco escapulares, uno de peroné y uno de gracilis. El seguimiento a largo plazo nos permite mostrar la gran adaptabilidad de los colgajos libres, su resistencia y su valor como procedimiento reconstructivo de primera opción.

Palabras clave Microcirugía, Colgajos libres, Secuelas de traumatismos.

Código numérico 158336
Abstract

Free flaps are useful to solve complex problems. Whenever there is an extensive loss of tissues or when other reconstructive methods have failed, they may provide the means to restore shape and function. This paper deals with five patients in whom eleven free flaps were used (two in four patients and three in one more case) to solve complex problems. Furthermore, long-term results are reported, with follow-up ranging from 7 to 17 years Indications to use more than one free flap in a patient are: replacing a first flap that was lost, a highly complex problem, the surgeon's expertise, or when the patient wish for a similar reconstruction. In this series, complexity of the problem was the main indication for the double method. The recipient zone was the lower extremities in four of the patients and the face in the fifth. The etiology were burn sequelae in two, post-traumatic sequelae in two and postsurgical and mielomeningocele sequelae in one. Four latissimus dorsi flaps, five scapular flaps one peroneus and one gracilis flaps were used. The recipient sites and surgical technique are described. Long-term follow-up makes it possible to demonstrate the outstanding adaptability of free flaps, their resilience and their usefulness as a first-choice reconstructive procedure.

$\begin{array}{ll}\text { Key words } & \text { Microsurgery, Free flaps, Trauma seque- } \\ & \text { lae. } \\ \text { Código numérico } & 158336\end{array}$




\section{Introducción}

Los colgajos libres resuelven problemas complejos. En situaciones en donde existe gran pérdida de tejidos u otros métodos reconstructivos ya han fracasado se puede lograr restablecer la forma y la función utilizándolos. Creemos que actualmente su uso debe ser de primera opción. El conocimiento de la técnica es fundamental, pero en casos complejos la creatividad juega un papel muy importante (1). Entre las indicaciones para efectuar más de un colgajo libre en un mismo paciente se encuentran: un segundo colgajo para reponer un primer colgajo perdido, necesidad de más tejido para defectos muy grandes, correcciones secundarias como aumento de volumen sobre todo en cirugía de cabeza y cuello $(1,2)$ o como tratamiento de elección por el cirujano (3-6).

En este trabajo se presentan 5 pacientes en los que se usaron 11 colgajos libres ( 2 por paciente en cuatro casos y un caso que recibió tres) en la reconstrucción de padecimientos complejos.

Asímismo se muestran resultados a largo plazo con un seguimiento mínimo de 7 años y máximo de 17 años.

\section{Material y Método}

Este trabajo lo componen 5 pacientes, 3 masculinos y 2 femeninos de $6,13,18,25$ y 50 años de edad (media 27.2) en el momento de la primera intervención quirúrgica; todos portadores de lesiones complicadas. Cuatro pacientes recibieron los colgajos en miembros inferiores y uno en la cara.

Las etiologías de los defectos fueron las sigientes. Paciente 1 (Fig. 1) con secuelas de necrosis tisular postquirúrgica, cicatriz retráctil y ulceraciones como secuela de mielomeningocele en los pies izquierdo y derecho, en el que se realizaron dos colgajos de dorsal ancho y un gracilis. Paciente 2, con secuelas de herida por proyectil de arma de fuego en cara, en el que se empleó un colgajo escapular y otro de peroné. Paciente 3 con secuelas de quemaduras en huecos poplíteos, en el que se realizaron 2 colgajos escapulares. Paciente 4 (Fig. 2) con secuelas de fracturas expuestas en talón y pierna, en el que se practicaron colgajo escapular y dorsal ancho. Paciente 5 (Fig. 3) con secuelas de quemaduras en maleolo externo y pierna, en el que se realizaron un colgajo escapular y un colgajo de dorsal ancho.

Tres de los pacientes (los casos 3, 4 y 5) habían sido tratados previamente con injertos de piel; los otros dos (casos 1 y 2) no habían sido sometidos a ningún intento reconstructivo.

Los colgajos utilizados fueron 4 de dorsal ancho, 5 escapulares, 1 de peroné y 1 de gracilis.
Cuando fue posible se trabajó con dos equipos quirúrgicos, uno que preparaba la zona receptora y otro que disecaba el colgajo. La localización y aislamiento de los vasos receptores siempre fue hecha por el cirujano responsable y antes de disecar el colgajo, ya que se debe valorar su estado y si hay necesidad de injertos de vena.

El paciente número 1 recibió 3 colgajos libres: 2 en el pie izquierdo y 1 en el derecho. Otros dos pacientes, en diferente extremidad inferior (pacientes 3 y 4 ). El paciente 5 recibió 2 colgajos en una sola extremidad y el que los recibió en la cara (paciente 2) lo hizo en la hemicara derecha.

Las arterias receptoras fueron tibial anterior y tibial posterior y ramas musculares poplíteas en las extremidades y carótida externa en la cara. Las venas receptoras fueron la safena mayor, safena menor, comitantes de las tibiales y ramas poplíteas en las extremidades y la yugular interna en la cara.

Las anastomosis arteriales fueron término-lateral en 3 pacientes (casos 1,4,5) término-terminales en uno (paciente 3) y con injertos de vena en otro (paciente 2). Las anastomosis venosas fueron termino-terminales en 4 (casos 1, 3, 4,5) y termino-laterales en uno (paciente 2).

En los pacientes 2 y 5 se usaron los mismos vasos como receptores en ambos colgajos (en el 2 la carótida externa y yugular y en el 5 la tibial anterior) a diferente nivel. No se requirió de inmovilizaciones especiales en ningún caso, ni tan siquiera en los niños; un vendaje adecuado y una férula de reposo en extremidades fueron suficientes.

La monitorización de los colgajos se realizó por observación de la isla de piel; en el colgajo muscular (paciente 1) por el exudado seroso habitual que permite observar cierta humedad del mismo. A los colgajos óseos se les realizó gammagrafía a los tres días de postoperatorio.

Los pacientes recibieron tratamiento antimicrobiano (Cefalosporinas) de acuerdo a su edad y peso.

El seguimiento de los pacientes fue de 8 años para el paciente 1, 7 años en el paciente 2, 5 años en el paciente 3, 16 años en el paciente 4 y 17 años en el paciente 5. Los casos se resumen en la Tabla I.

\section{Resultados}

Presentamos los datos de 5 pacientes con un total de 11 colgajos libres, dos por paciente en cuatro casos $\mathrm{y}$ tres en el otro.

Todos los colgajos sobrevivieron. Se permitió la remodelación espontanea de los colgajos, sobre todo en niños, en donde nuestra experiencia ha demostrado que rara vez es necesario efectuar adelgazamiento 


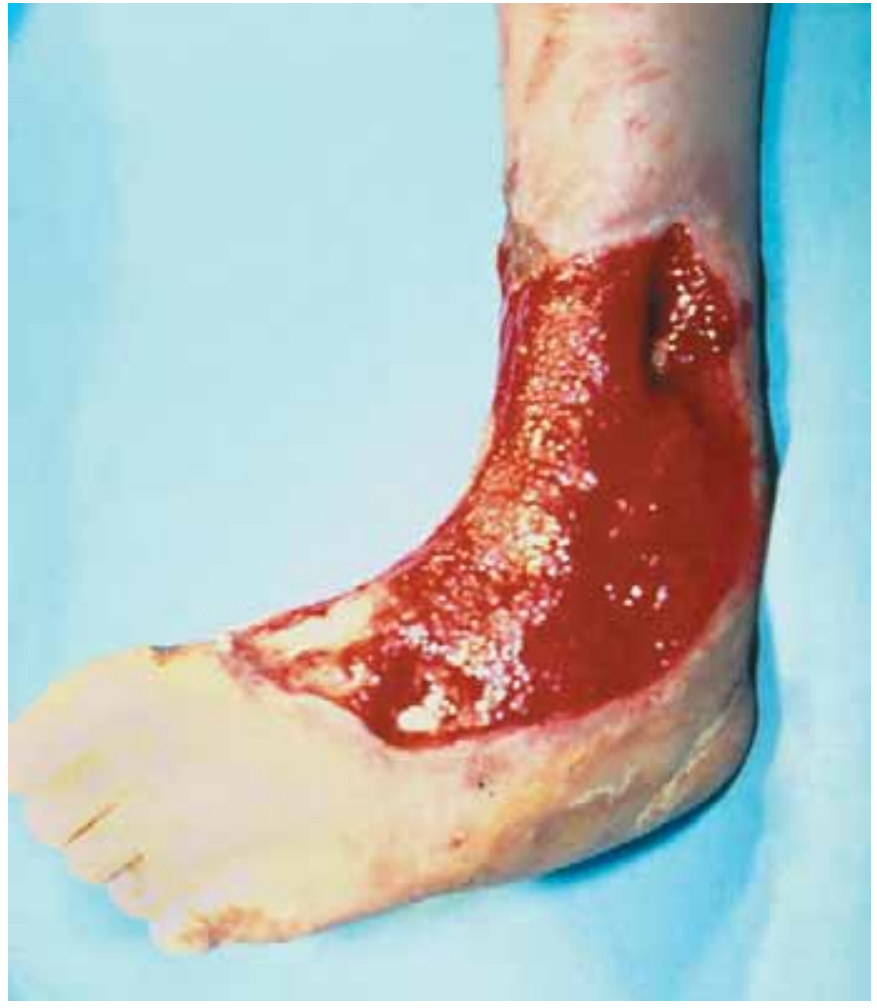

Fig. 1 a) Preoperatorio. Primer colgajo. Dorsal ancho. Áreas cruentas con exposición ósea en pierna y pie izquierdos.

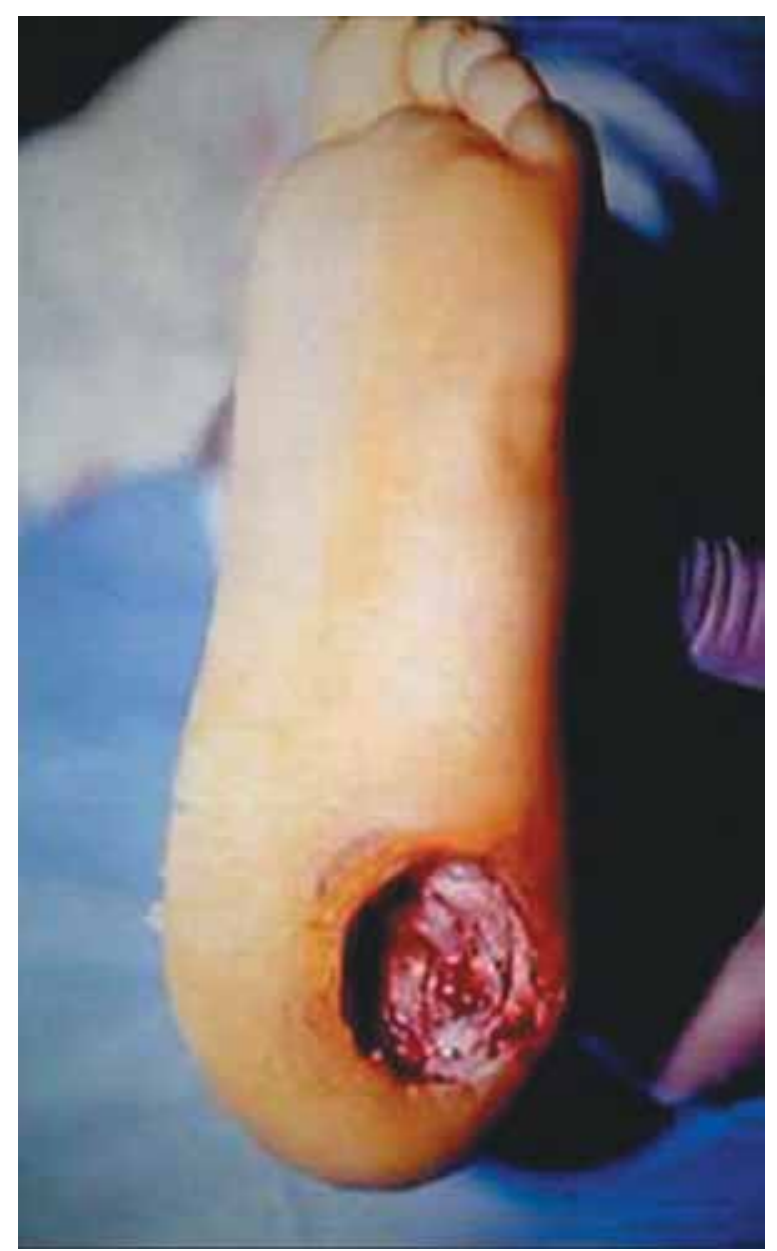

Fig. 1 c) Preoperatorio Segundo colgajo Ulceración en talón izquierdo.

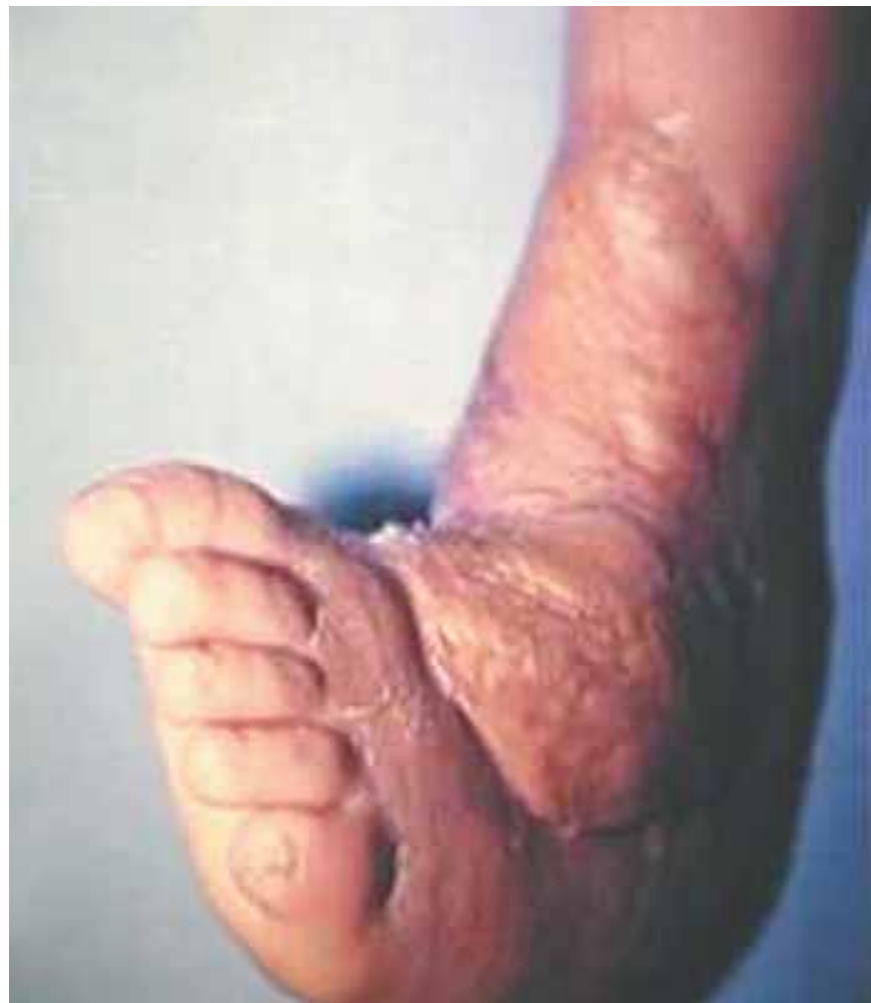

Fig. 1 b) Postoperatorio a los 6 meses después del primer colgajo. En este tiempo se hizo la alineación del pie.

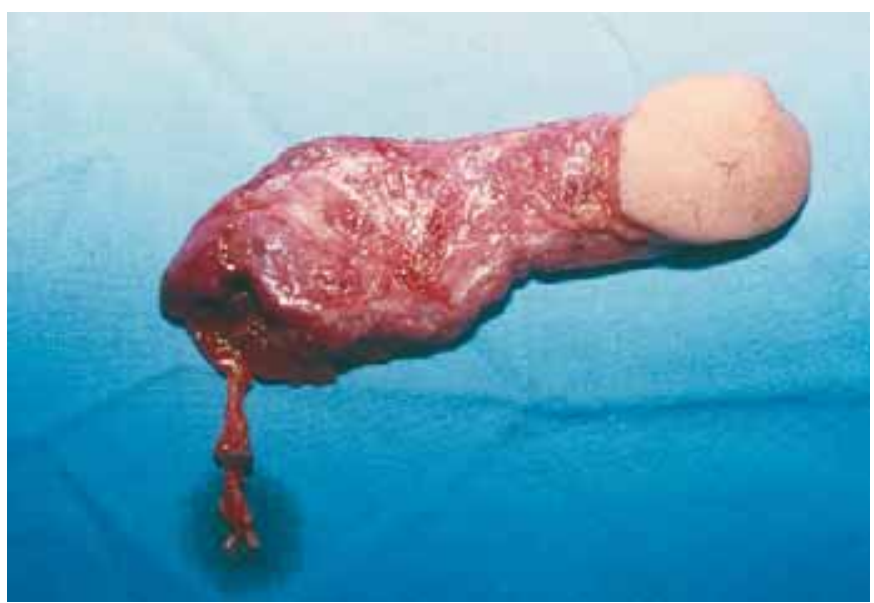

Fig. 1 d) Colgajo Libre de Dorsal Ancho para talón izquierdo 


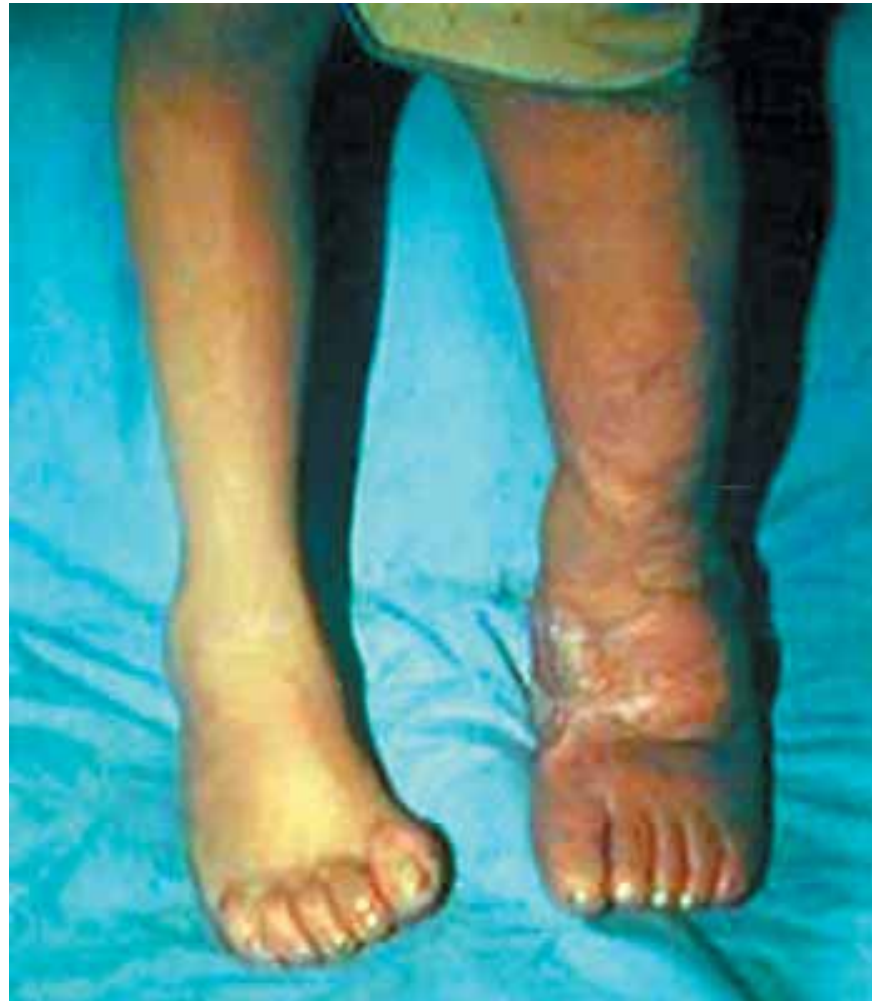

Fig. 1 e) Tres años después de los dos primeros colgajos y corrección del tobillo.

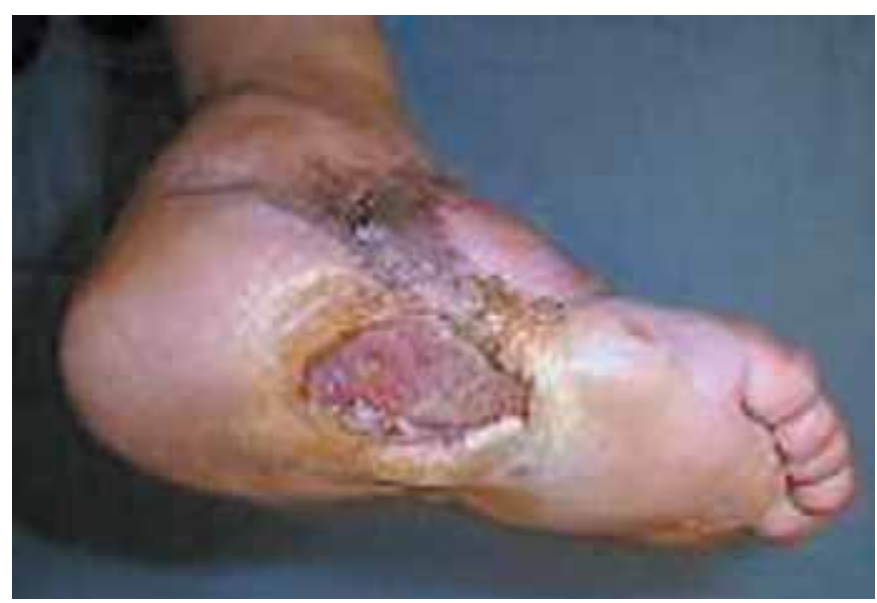

Fig. 1 g) Nueva ulceración ahora en pie derecho.

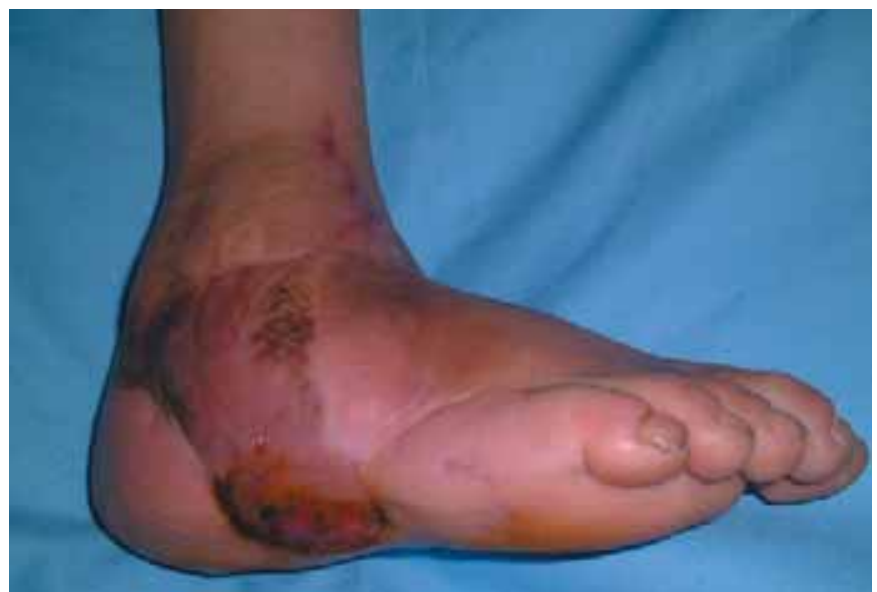

Fig. 1 i) Tres meses después del tercer colgajo

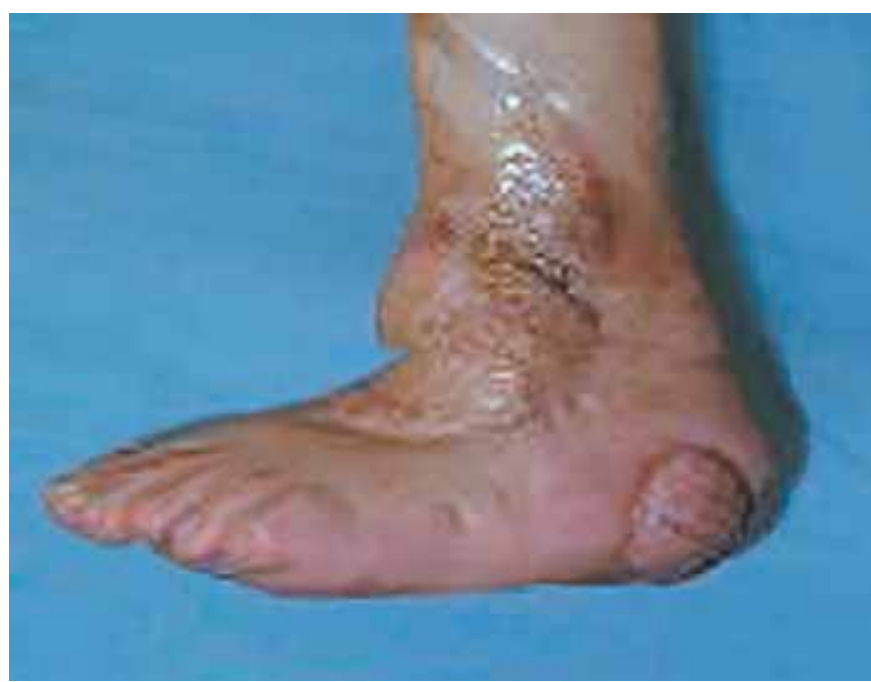

Fig. 1 f) Vista lateral a los 3 años de los primeros colgajos.

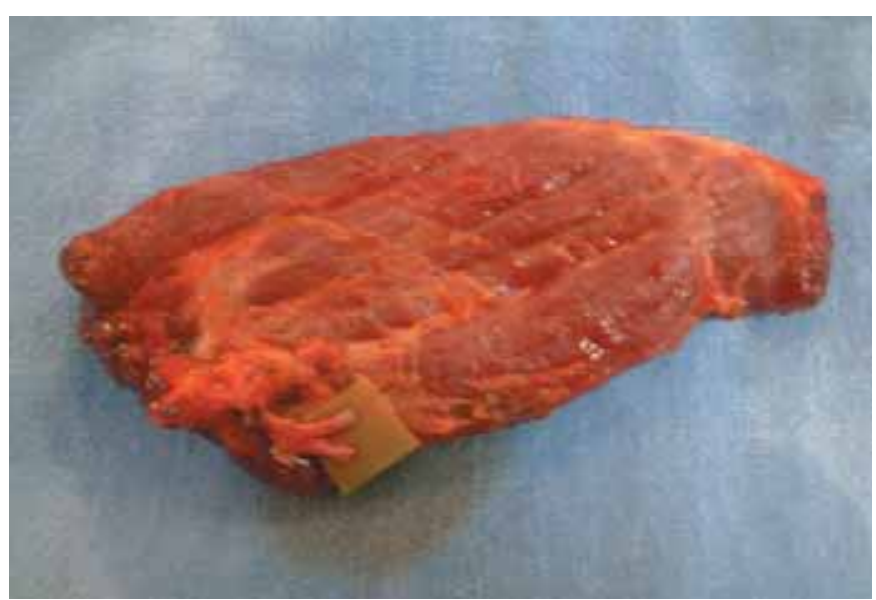

Fig. 1 h) Tercer colgajo libre Gracilis.

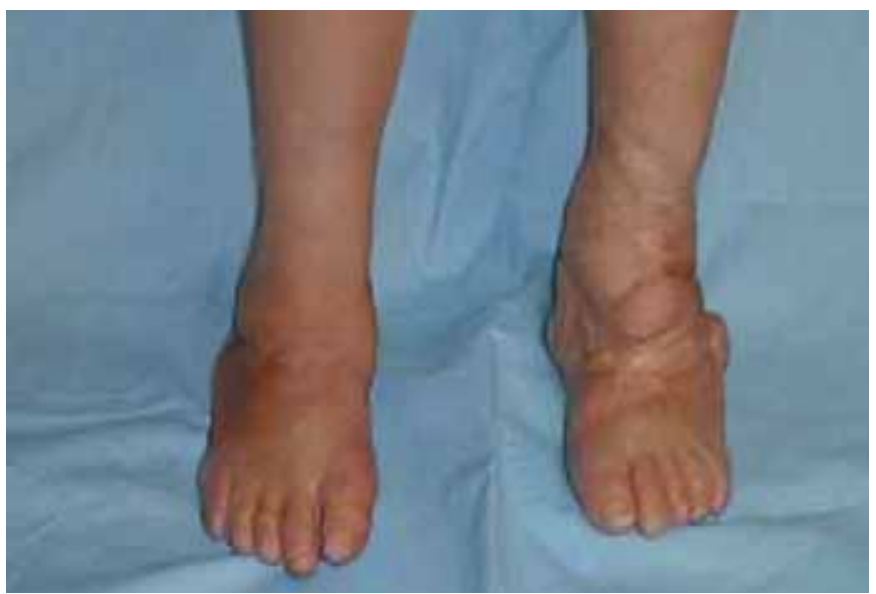

Fig. 1 j) Siete años después del primer colgajo. 


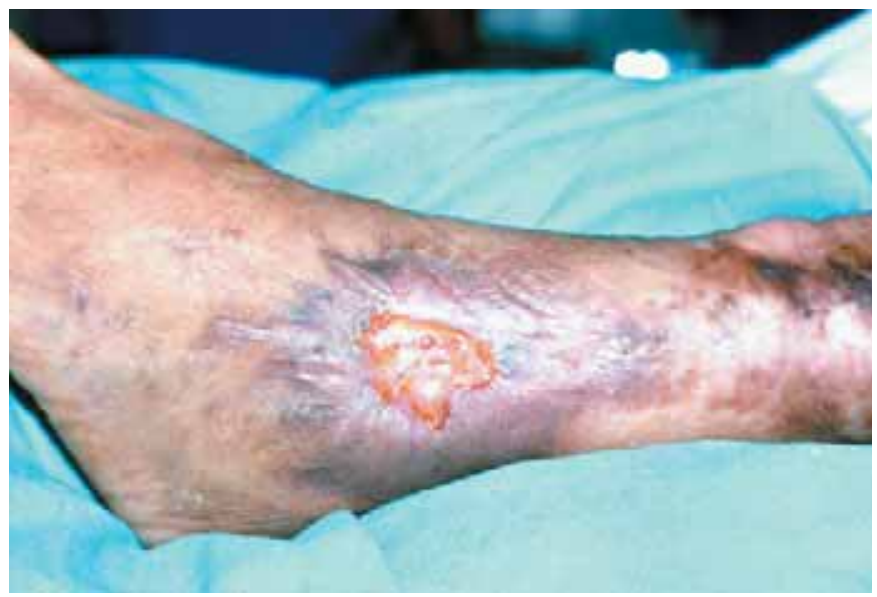

Fig. 2 a) Preoperatorio primer colgajo, ulcera crónica post-quemadura en maleolo externo.

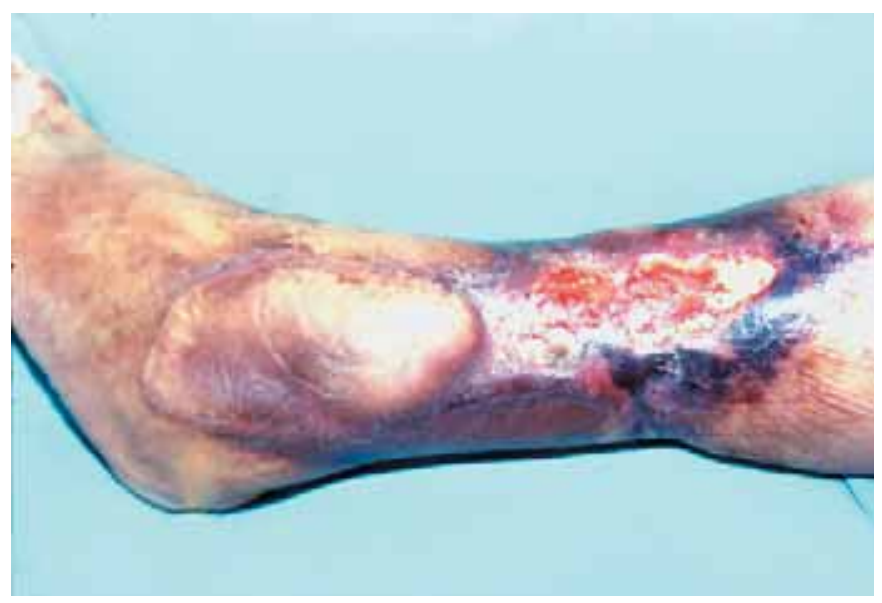

Fig. 2 c) Preoperatorio segundo colgajo. Ulcera en pierna post-quemadura más insuficiencia venosa.

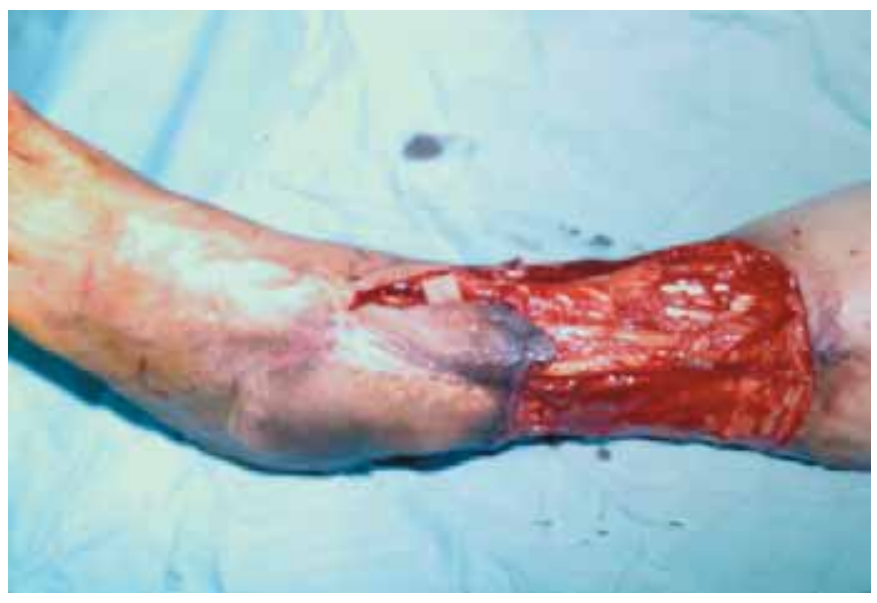

Fig. 2 e) Intraoperatorio. Gran defecto tisular después del desbridamiento. Las microanastomosis vasculares se realizaron en la misma tibial anterior (arteria y vena) del primer colgajo a un nivel más cefálico.

o reacomodo de los colgajos. Solamente en un colgajo, el primero de la paciente 5, se efectuó adelgazamiento posterior. Cuando se utilizaron colgajos músculocutáneos, presentaron hipotrofia y remodelación espontánea.

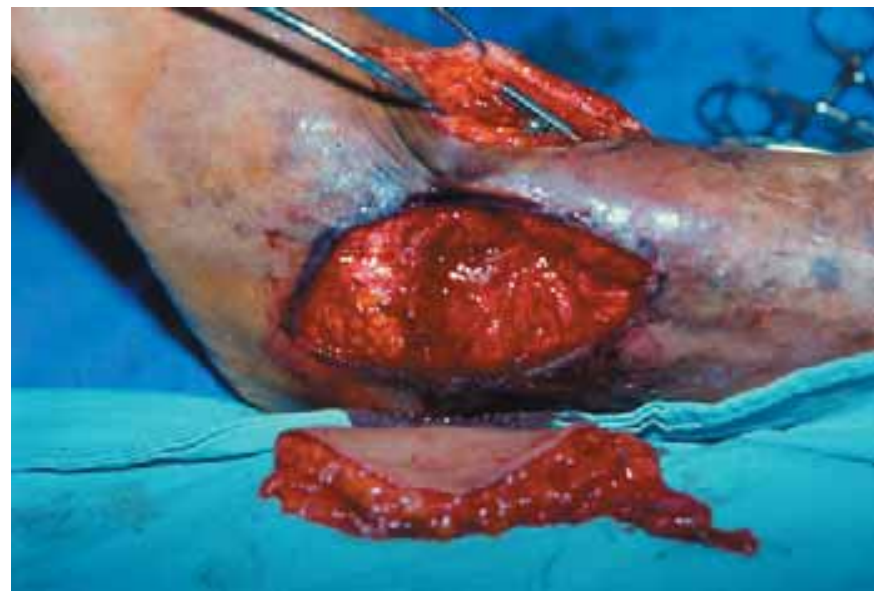

Fig. 2 b) Intraoperatorio. Colgajo libre escapular.

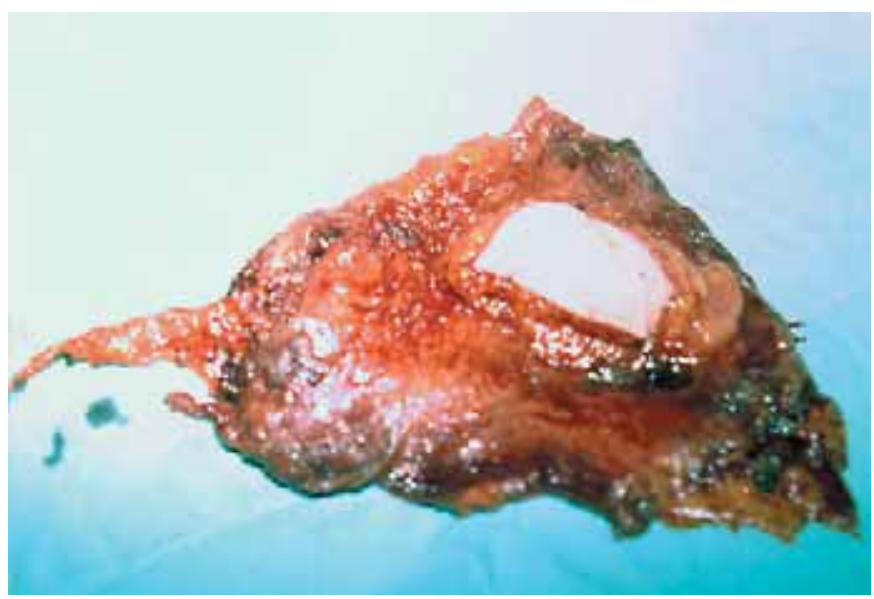

Fig. 2 d) Intraoperatorio. Colgajo libre de dorsal ancho.

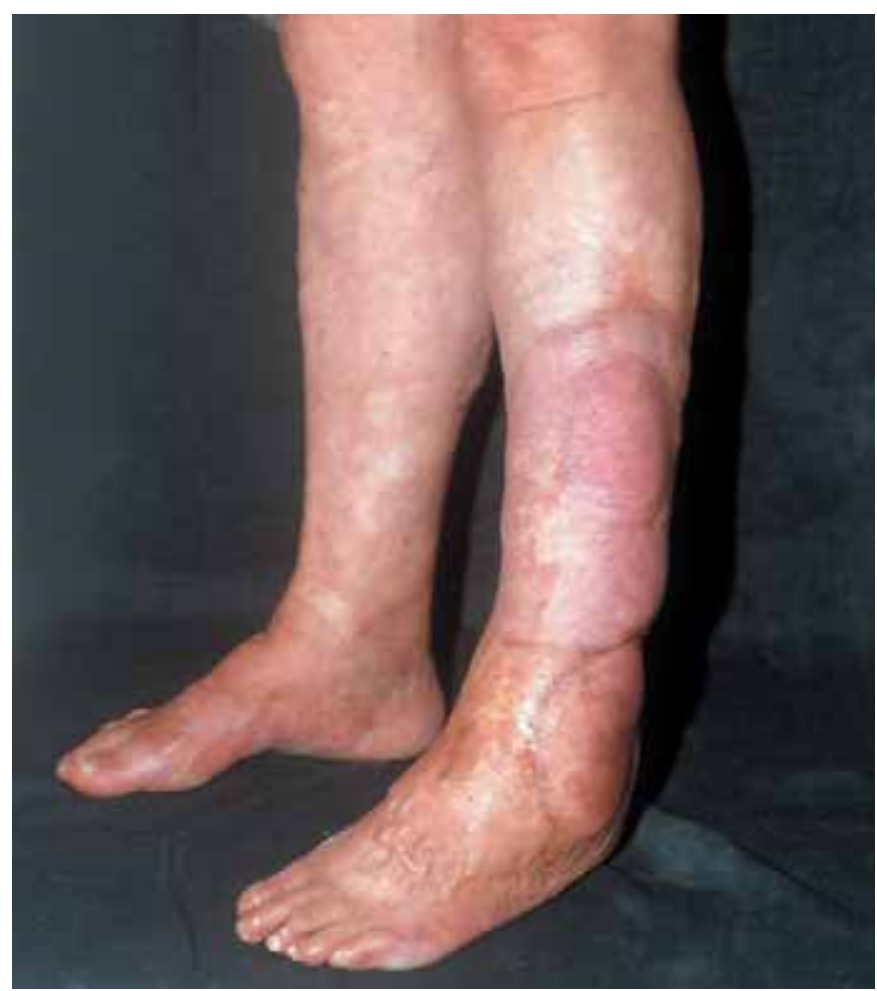

Fig. 2 f) Postoperatorio a los 17 años. 


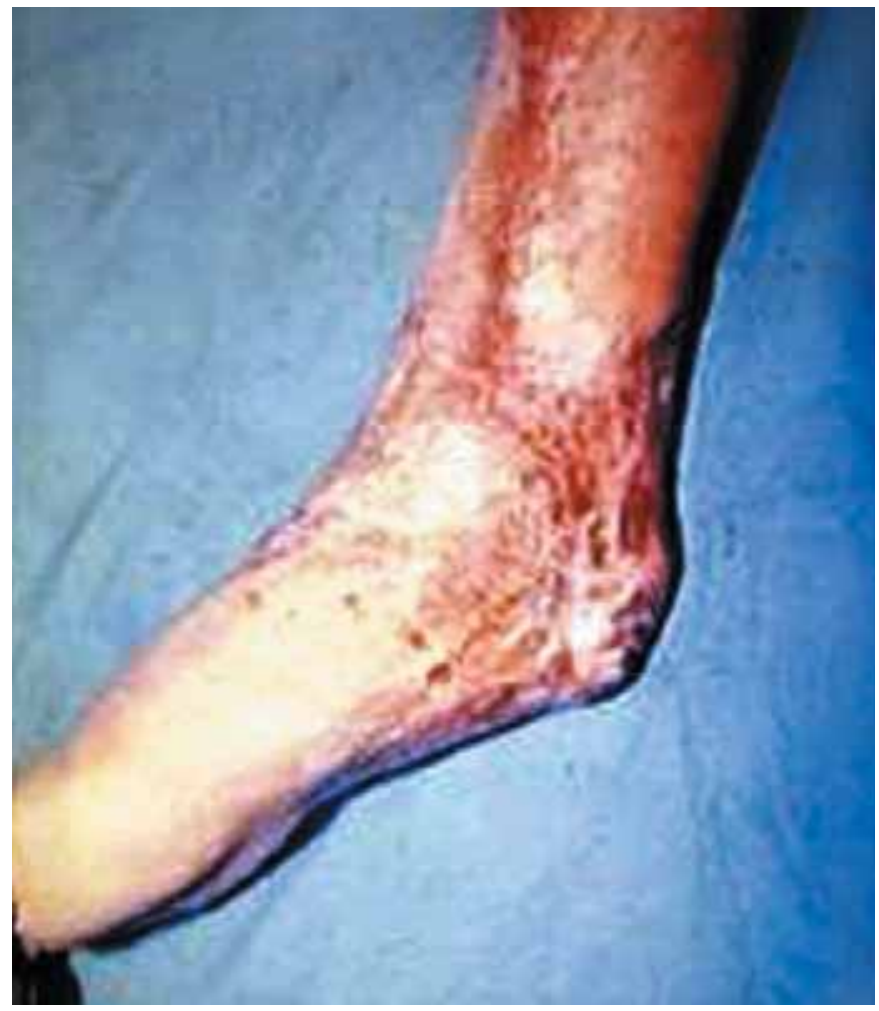

Fig. 3 a) Preoperatorio primer colgajo. Secuelas de pérdida osteocutánea en pie, el calcáneo solo cubierto por injertos de piel.

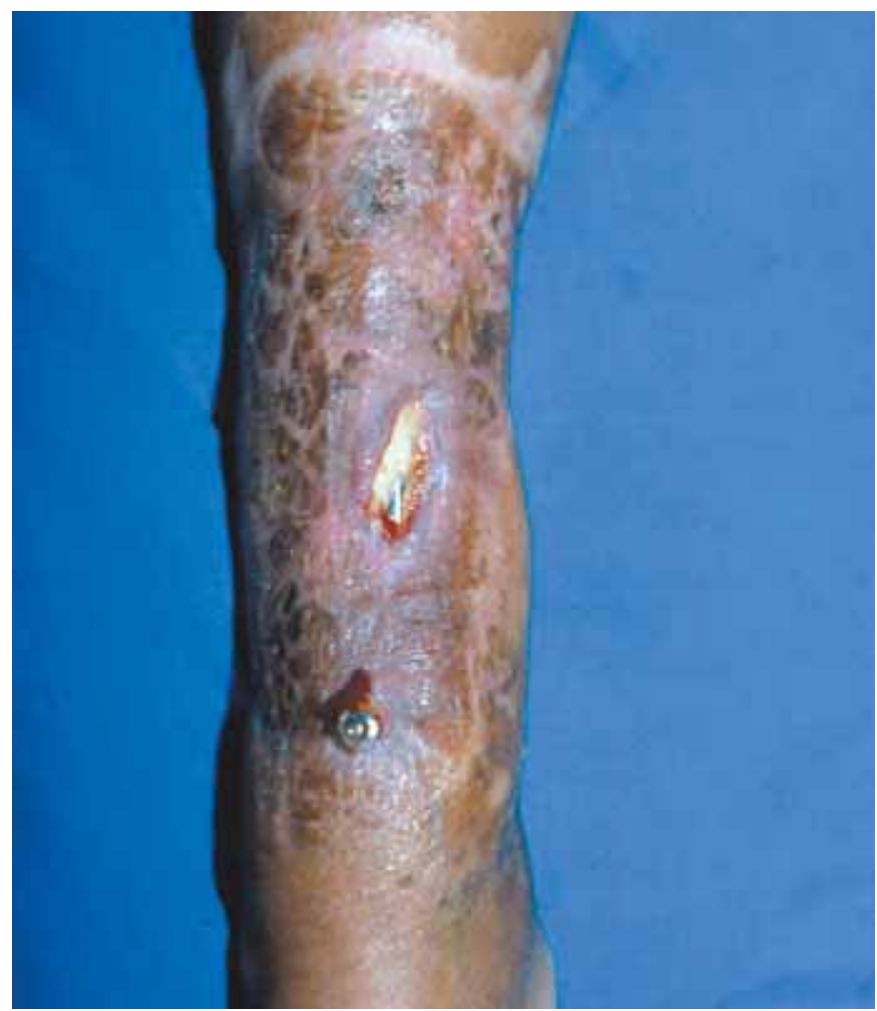

Fig. 3 c) Preoperatorio segundo colgajo. Secuelas de pérdida osteocutánea en pierna, exposición ósea y de material de osteosíntesis.

No existieron complicaciones en las áreas donadoras; las cicatrices de los colgajos escapulares siempre tienden a la hipertrofia que mejora con el tiempo.

Los colgajos colocados en áreas de apoyo del

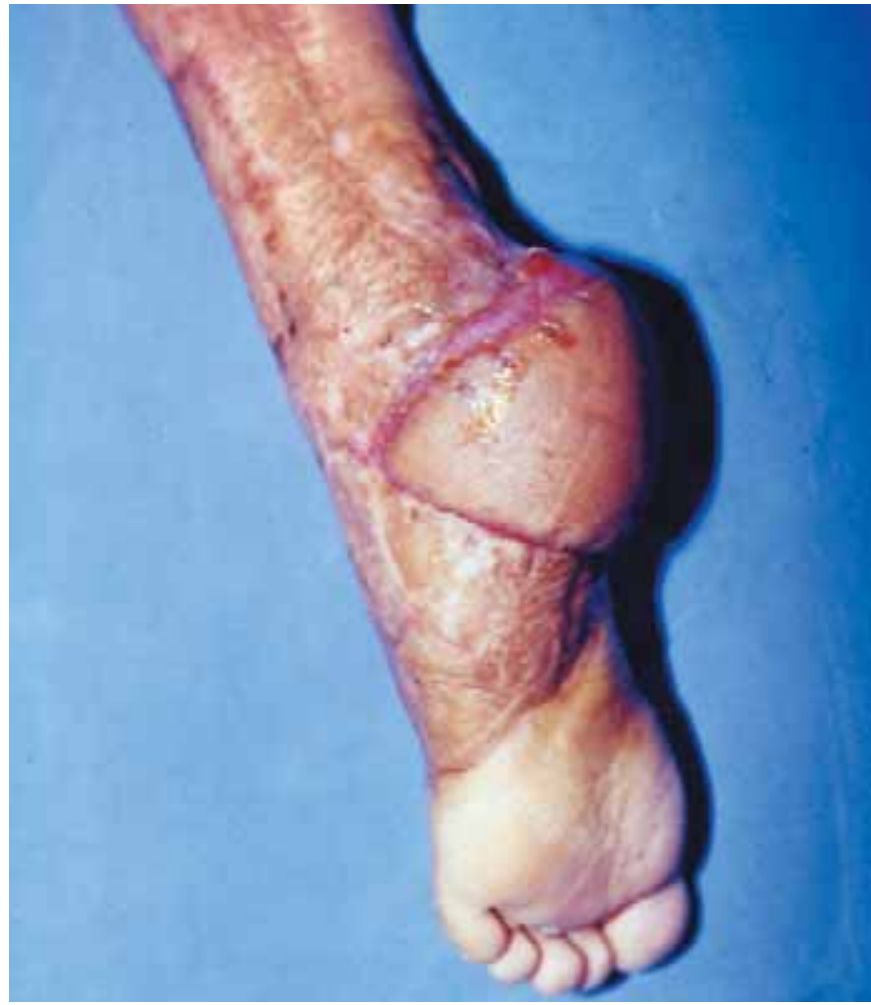

Fig. 3 b) Postoperatorio colgajo libre escapular.

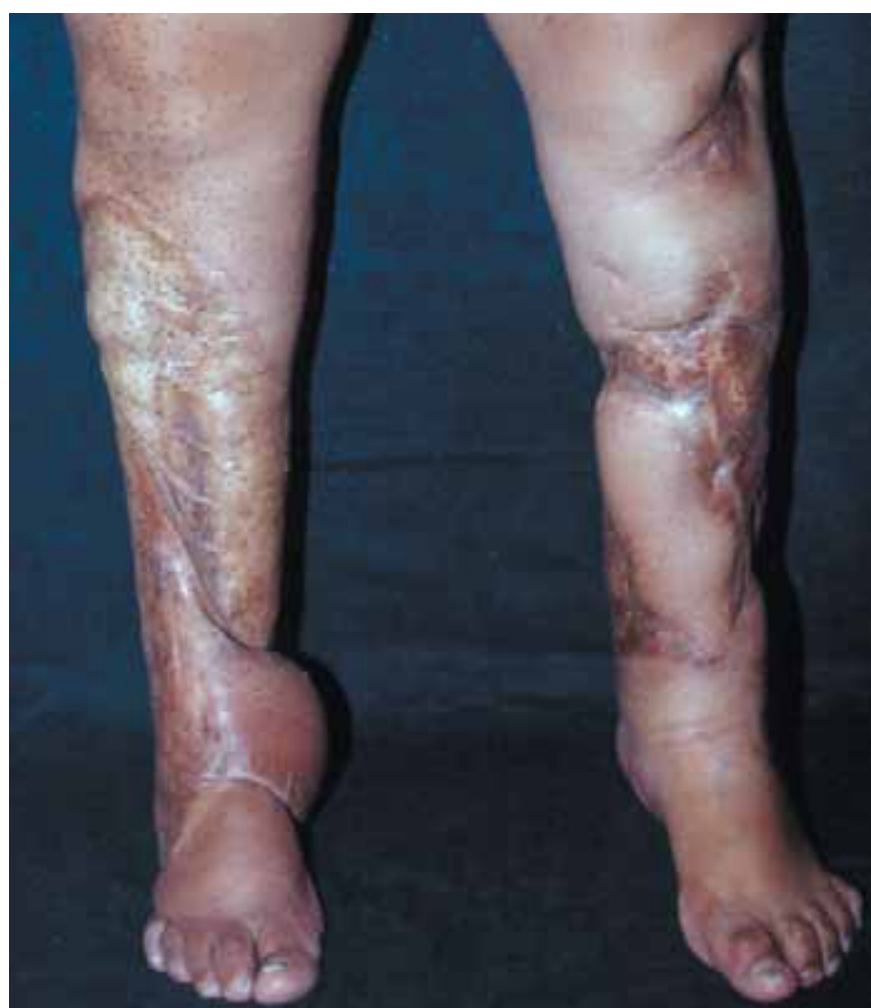

Fig. 3 d) Postoperatorio a los 8 años.

paciente 1 presentaron ulceraciones debido a alteraciones en la sensibilidad por su problema de origen, sin embargo con curas periódicas y cuidados de higiene no ha requerido nuevas intervenciones quirúrgicas. 


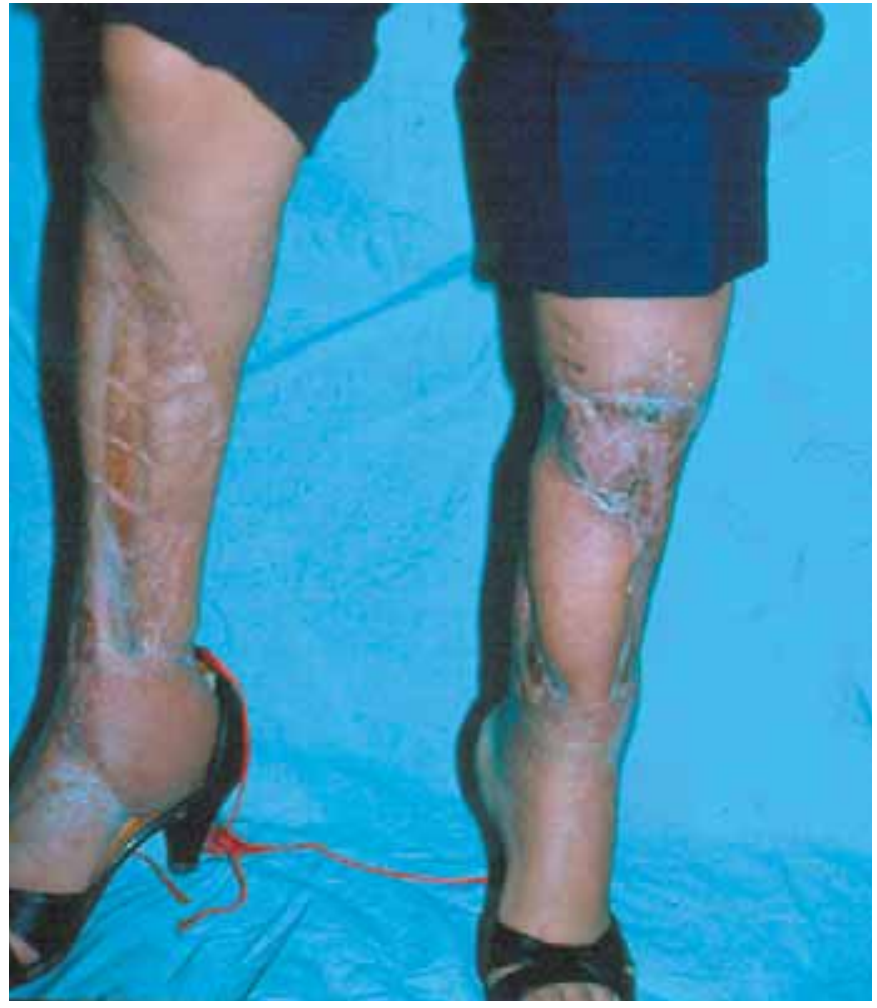

Fig. 3 e) Postoperatorio a los 15 años. Se aprecian ambos colgajos.

\section{Discusión}

Hace más de tres décadas que los colgajos libres son utilizados para procedimientos reconstructivos; al principio su uso se reservaba para cuando otros métodos habían fallado y como última opción se ofrecía el transplante tisular microquirúrgico. Así, usados en casos verdaderamente complicados y dando resultados espectaculares, fue como su aceptación creció para ser hoy en día procedimientos de primera elección.

La experiencia con la técnica microquirúrgica ha llevado a los cirujanos plásticos a usar en un mismo paciente más de un solo colgajo libre $(1-3,5,6)$.

Pensamos que las indicaciones para usar un segundo colgajo libre deben ser: para reponer un primer colgajo perdido, como aumento de volumen para remodelación de ciertas áreas, por grave complejidad del problema, cuando la experiencia del cirujano permita hacer uso del colgajo libre secundario, y cuando el paciente o sus familiares, en el caso de los niños, expresen el deseo de que se les realice un segundo procedimiento después de discutirlo con el cirujano (4).

En esta serie que presentamos, la indicación principal para usar un segundo colgajo libre fue en primer lugar la complejidad del problema y secundariamente el deseo expreso del paciente de que se le realizara esa cirugía. Se presentó mayor dificultad para efectuar un segundo colgajo libre en el sitio o muy cercano del primero (2) en nuestra serie en tres pacientes (los número 1,2 y 5). No encontramos problemas con los vasos receptores siempre que el planteamiento fue cuidadoso, lo que siempre recomendamos.

Fundamental en este trabajo es la valoración a largo plazo; nuestro seguimiento mínimo de 7 años y máximo de 17 nos permite afirmar que hay gran adaptación del tejido a su nuevo sitio, existe una mimetización y en algunos casos parece como si el nuevo tejido siempre hubiera estado ahí. Existe además una remodelación espontánea, por lo que se recomienda, sobre todo en niños, esperar a que ésta se produzca evitando así cirugías posteriores. Es de señalar también su resistencia, ya que colocados en sitios de apoyo y roce toleran las actividades normales de los pacientes.

Estas observaciones a largo plazo demuestran sin duda el valor de los colgajos libres como procedimiento reconstructivo de primera elección.

TABLA I

\begin{tabular}{|c|c|c|c|c|c|c|}
\hline DEFECTO & SEXO & EDAD & DIAGNOSTICO & COMPLICACIONES & COLGAJOS & SEGUIMIENTO \\
\hline $\begin{array}{l}\text { CICATRIZ RETRACTIL ANTEPIE } \\
\text { EXPOSICION DE CALCANEO }\end{array}$ & MASC & 6 & $\begin{array}{l}\text { SECUELAS DE NECROSIS } \\
\text { CUTANEA POSTQUIRURGICA } \\
\text { ULCERAS POR COMPRESION } \\
\text { (SECUELAS DE MIELOMENINGOCELE) }\end{array}$ & $\begin{array}{l}\text { ULCERACIONES } \\
\text { REPETIDAS. }\end{array}$ & $\begin{array}{l}\text { DORSAL ANCHO } \\
\text { (2) } \\
\text { GRACILIS }\end{array}$ & 7 AÑOS \\
\hline $\begin{array}{l}\text { PERDIDA TISULAR } \\
\text { EN HEMICARA DERECHA }\end{array}$ & MASC. & 13 & $\begin{array}{l}\text { SECUELAS DE HERIDA POR } \\
\text { PROYECTIL ARMA DE FUEGO }\end{array}$ & NO & $\begin{array}{l}\text { ESCAPULAR } \\
\text { PERONE }\end{array}$ & 7 AÑOS \\
\hline $\begin{array}{l}\text { CICATRICES RETRACTILES } \\
\text { EN HUECOS POPLITEOS }\end{array}$ & MASC. & 18 & SECUELAS DE QUEMADURAS & NO & $\begin{array}{l}\text { ESCAPULAR } \\
\text { (2) }\end{array}$ & 7 AÑOS \\
\hline $\begin{array}{l}\text { EXPOSICION DE CALCANEO } \\
\text { Y TIBIA }\end{array}$ & FEM. & 25 & $\begin{array}{l}\text { SECUELAS DE } \\
\text { FRACTURAS EXPUESTAS }\end{array}$ & NO & $\begin{array}{l}\text { ESCAPULAR } \\
\text { DORSAL ANCHO }\end{array}$ & 16 AÑOS \\
\hline $\begin{array}{l}\text { ULCERAS CRONICAS EN } \\
\text { MALEOLO EXTERNO } \\
\text { Y PIERNA DERECHA }\end{array}$ & FEM & 60 & SECUELAS DE QUEMADURAS & NO & $\begin{array}{l}\text { ESCAPULAR } \\
\text { DORSAL ANCHO }\end{array}$ & 17 AÑOS \\
\hline
\end{tabular}


Podemos concluir de nuestra práctica y experiencia que ante problemas reconstructivos complejos, usar uno o más colgajos libres en un solo paciente está ampliamente justificado y permite al cirujano poder garantizar a los pacientes resultados permanentes a largo plazo.

\section{Dirección del autor}

Dr. Carlos Olvera Caballero

25 Oriente 1809

Colonia Bellavista

Puebla, Pue. 72540 México

e-mail: drcarlosolvera@yahoo.com
1. Burt, J.D., Burns, A.J., Muzaffar, A.R., Byrd, S.H. et al.: "Total soft-tissue reconstruction of the middle and lower face with multiple simultaneous free flaps in the pediatric patient". Plast. Reconst. Surg. 2000, 105:2440.

2. Abdel-Wahab A.A., Baldwyn, J.B., Gürlek, A., Miller, J.M., Kroll, S.S. et al.: "Second free flaps in head and neck reconstruction". J. Reconst. Microsurg 1998,14:365.

3. Urken, M.L. Weinberg, H. Vickery, C. et al.: "The combined sensate radial forearm and iliac crest flaps for reconstruction of significant glossectomy-mandibulectomy defect". Laryngoscope 1992, 102:543.

4. Pickford, M.A., Soutar, D.S.: "Intraoral reconstruction using second free flap for recurrent of metachronous carcinoma". Brit. J. Plast. Surg. 1995, 48:559.

5. Kroll, S.S., Schusterman, M.A., Reece, J.P. et al.: "Choice of flap and incidence of free flap success". Plast. Reconst. Surg.1996, 98:459.

6. Sanger, J.R., Yosif, N.J., Matloub, H.S. et al.: "Reconstruction of lower third of the face with three simultaneous free flaps". Plast Reconst. Surg.1994, 94:709. 